Original Article

\title{
Dietary Intervention on Precancerous Cervical Lesion among Women in Selected Rural Area of Bangalore
}

\author{
J. Kamala \\ HOD, Associate professor, Obstetrics and Gynaecological Nursing \\ Kempegowda College of Nursing, Bangalore. \\ Correspondence \\ J. Kamala \\ HOD, Associate professor, Obstetrics and Gynaecological Nursing \\ Kempegowda College of Nursing, Bangalore \\ M obile : +91 9980468832 E-mail : kamala.chandrashekar@gmail.com
}

\begin{abstract}
Introduction : Cervical cancer is one of the leading cancers among women, which affects approximately 4,90,000 women each year, resulting in approximately 2,70,000 deaths worldwide. Epidemiological studies have shown that $70-90 \%$ of all cancers are environmental. Lifestyle related factors are the most important and preventable among the environmental exposures. Dietary practices, reproductive and sexual practices will account for $20-30 \%$ of cancers. Dietary intervention by millet based antioxidants has been shown to dramatically reduce the incidence of PCCL.
\end{abstract}

Aim : The aim of the study was to evaluate the effectiveness of dietary intervention on precancerous cervical lesion among women.

Methodology : A Quasi experimental research design, convenient sampling technique was used to collect data from 100 women in Bangalore rural. Data was collected by using structured interview schedule and VIA observation rating scale followed by dietary intervention through administration of millet based antioxidants for 90 days to women in experimental group.

Statistical Analysis: The data was collected and analyzed using software statistical package for social sciences (SPSS) version 12.0.

Results: The mean PCCL after dietary intervention was 3.0 ( $S D=2.5)$ significantly less than the pretest $7.04(S D=1.4), t=20.3(p<0.05)$.

Conclusion : It was found that dietary intervention was significantly effective in reducing PCCLamong women

Keywords : Effectiveness, Dietary intervention, PCCL, Women

\section{Introduction}

The health of women represents the health status of any country. Women form a vulnerable or special risk group ${ }^{1}$. A women's health is her total well-being, not determined solely by biological factors and reproduction, but also by effects of work load, nutrition, stress, war and migration, among others. Blame it on changing lifestyle or lesser body resistance; women's growing health issues are catching everyone's eyes. Five most common health problems among women today are Breast cancer, Stroke, Polycystic

\begin{tabular}{|c|}
\hline Access this article online \\
\hline Quick Response Code \\
\hline
\end{tabular}
ovarian disease, Female sexual arousal disorder and Obesity².

Cancer a dreadful disease is an unusual or abnormal uncoordinated growth of tissue beyond the normal tissue in any particular area of the body ${ }^{3}$. According to the National Cancer Registry Programme of India, cancers of the uterine cervix and breast are the leading malignancies noted in Indian women ${ }^{4}$. Cervical cancer represents the second most common cancer in women world wide. The incidence varies geographically with rates in industrialized nations of 10 per $1,00,000 \&$ in developing countries of 40 per $1,00,000$. Approximately $80 \%$ of all new cases are diagnosed in developing nations of the world ${ }^{5}$.

Cervical cancer is one of the leading cancers among women, which affects approximately 4,90,000 women each year, resulting in approximately 2,70,000 deaths worldwide. It has been estimated that in India, 1,00,000 new cases of cervical cancer occur annually, and $70 \%$ or more of these cancers are stage III or higher at the time of diagnosis. ${ }^{4}$. There has been a regular campaign against cervical cancer for 30 years in India, but this has had little 
impact on the morbidity and mortality from the disease, with India ranking fourth worldwide. The cancer mostly affects middle- aged women (between 40 and 55 years), especially those from the lower economic status who fail to carry out regular health check-ups due to financial inadequacy. In urban areas, cancer of the cervix account for over $40 \%$ of cancers while in rural areas it accounts for $65 \%$ of cancers as per the information from the cancer registry in Barshi ${ }^{6}$.

Carcinoma of cervix is one of the most common forms of cancers in women and is the second biggest cancer mortality worldwide. The world wide incidence is found to be 500000 per year, about half of which results in death. Over 80 percentage of incidence occurs in developing countries with 25 percentage is estimated to occur in India'. A very high risk of cervical cancer is observed in India. India accounts for a quarter $(1,26,000$ new cases, 71,000 deaths around the year 2000) of the world burden of cervical cancer $(4,71,000 \text { new cases and } 2,33,000 \text { deaths })^{8}$. Control of cervical cancer by early detection and treatment is one of the priorities of the National cancer control programme of India9. In Bangalore, it is 26.4 per 1,00,000 women ${ }^{10}$. Though a slow and steady decline in cervical cancer incidence rates is observed in some urban populations, the rates are still high, particularly in rural areas, and the absolute number of cases is on the increase due to population growth (NCCP) ${ }^{11}$.

Vinegar has proved to be useful as a cheap and effective screening test for cervical cancer. The researcher who established its potential say it could improve the chances of preventing cancer in developing world. At the moment, 5\% of women in the developing world are screened for cervical cancer. In industrialized nations the figure is $70 \%$. Vinegar acetic acid could be used where the standard PAP smear is unavailable or too expensive. In the UK, the NHS cervical screening programme estimates that testing for early signs prevents up to 3,900 cancers each year ${ }^{12}$. According to WHO about 2,88,000 women a year die from cervical cancer. Most live in the developing world. With cervical cancer, early screening is the ounce of prevention that can cure. No woman should be denied that opportunity. ${ }^{13}$

What you eat can hurt you, but it can also help you. One of the easiest and most effective ways to promote good health and to help protect against cancer is with our diet. The national cancer institute and The American cancer society estimates that roughly one third of all cancer deaths may be diet related. Food rich in anti-oxidants could playa preventive role ${ }^{6}$.

\section{Objective}

1. To evaluate the effectiveness of dietary intervention on Pre cancerous cervical lesion (PCCL) among women in selected rural area, Bangalore.

\section{Hypothesis}

$\mathbf{H}_{1}$ : There will be significant difference between the Pre cancerous cervical lesion (PCCL) before and after dietary intervention among women in experimental group.

$\mathbf{H}_{2}$ : There will be a significant difference in the mean difference of Pre cancerous cervical lesion (PCCL) between women in experimental and control group.

\section{Materials and Methods}

A Quasi experimental research design, convenient sampling technique was used to collect data from 100 women who are residing in villages coming under Anugondanahalli P.H.C. Hoskete taluk, Bangalore rural. The study was explained and informed consent was taken. Data was collected by using structured interview schedule and VIA (Visual inspection of acetic acid test) observation rating scale followed by dietary intervention through administration of millet based antioxidants to women in experimental group. Post test was conducted after 90 days to find out the effectiveness.

After obtaining ethical clearance and formal permission from higher authorities, data was collected from those who were willing to participate and included for the study. Confidentiality was assured to the entire subjects to get their co-operation. An informed consent was taken from all the subjects individually after explaining the objectives and purpose of the study. 


\section{Inclusion Criteria}

- Married women

- Women aged between 20-50yrs

- Sexuallyactive

- Non pregnant women

- Women with Grade I \& Grade II PCCL

\section{Exclusion Criteria}

- Women with Post-total hysterectomy status.

- Women who are already diagnosed Cervical cancer and under treatment.

- Women with frank visible ulcerative or Proliferative growth over the cervix.

- Menopause women

- Women with HPV Vaccination

- Women with dense aceto white area present for more than 3 minutes or grade III PCCL.

Tool 1: Sample characteristics.

Tool 2: Observational rating scale on VIA (Visual inspection of acetic acid test)

\section{Results}

The study results revealed that, majority of women in experimental group 24(48\%) were in the age group of 20 $30 y r s, 23(46 \%)$ had no formal education, $36(72 \%)$ were housewives, 50(100\%) were Hindus, 22(44\%) were in the income range of Rs $\angle=1000,30(60 \%)$ were belonging to Joint family, 45(90\%) were non vegetarians, $15(30 \%)$ had habit of tobacco chewing, 20(40\%) were married at the age of 14-16yrs, $49(98 \%)$ had no family history of genital malignancies, 50(100\%) did not have post coital bleeding and $32(64 \%)$ did not have history of white discharge. In menstrual variables 49(98\%) had regular menstrual cycle, $25(50 \%)$ had attained menarche at the age of 13yrs, $47(94 \%)$ had normal menstrual flow, 39(78\%) were using cotton cloths during menstruation, $40(80 \%)$ were reusing cloths used during periods, 40(80\%) were washing cloth with cold water and drying in sunlight, $40(80 \%)$ were changing cloths twice daily and $50(100 \%)$ were taking bath daily once. In sexual practice variables majority $20(40 \%)$ were exposed to sex at the age of 15-16yrs, 23(46\%) were having sex once a week, 28(56\%) were washing perineal area after the sex, nobody had history of multiple sexual partner, nobody used condom during sex and nobody practiced sexduring menstrual periods.

TABLE : 1 Classification of Respondents by Demographic variables $\quad \mathbf{N}=\mathbf{1 0 0}$

\begin{tabular}{|c|c|c|c|c|c|}
\hline \multirow[t]{2}{*}{ Characteristics } & \multirow[t]{2}{*}{ Category } & \multicolumn{2}{|c|}{ Control $(n=50)$} & \multicolumn{2}{|c|}{ Experimental $(n=50)$} \\
\hline & & $\mathrm{N}$ & $\%$ & $\mathrm{~N}$ & $\%$ \\
\hline Age & $20-30$ years & 26 & 52.0 & 24 & 48.0 \\
\hline \multirow[t]{2}{*}{ Education status } & No formal education & 16 & 32.0 & 23 & 46.0 \\
\hline & Higher secondary & 21 & 42.0 & 19 & 38.0 \\
\hline \multirow[t]{2}{*}{ Occupational status } & Private & 25 & 50.0 & 0 & 0.0 \\
\hline & House wife & 22 & 44.0 & 36 & 72.0 \\
\hline Religion & Hindus & 50 & 100.0 & 50 & 100.0 \\
\hline \multirow[t]{2}{*}{ Family income/month } & $4=$ Rs 1000 & 11 & 22.0 & 22 & 44.0 \\
\hline & Rs 1001 - 2000 & 33 & 66.0 & 21 & 42.0 \\
\hline Type of family & Joint family & 27 & 54.0 & 30 & 60.0 \\
\hline Type of Diet & Non vegetarians & 48 & 96.0 & 45 & 90.0 \\
\hline Habit & Tobacco chewing & 21 & 42.0 & 15 & 30.0 \\
\hline Age at marriage & 14 - 16yrs & 38 & 76.0 & 20 & 40.0 \\
\hline Age at menarche & 13yrs & 29 & 58.0 & 25 & 50.0 \\
\hline \multirow{2}{*}{$\begin{array}{l}\text { Family history of } \\
\text { genital malignancies }\end{array}$} & Yes & 01 & 02.0 & 01 & 02.0 \\
\hline & No & 49 & 98.0 & 49 & 98.0 \\
\hline Post coital bleeding & No & 50 & 100.0 & 50 & 100.0 \\
\hline \multirow{2}{*}{$\begin{array}{l}\text { Type of material used } \\
\text { during mensturation }\end{array}$} & Sanitary napkin & 16 & 32.0 & 11 & 22.0 \\
\hline & Cotton cloth & 34 & 68.0 & 39 & 78.0 \\
\hline \multirow[t]{2}{*}{ Reuse of cloth pad } & Yes & 34 & 68.0 & 40 & 80.0 \\
\hline & No & 16 & 32.0 & 10 & 20.0 \\
\hline
\end{tabular}


Table : 2 M ean PCCL before and after the dietary intervention among Experimental Group

$\mathrm{N}=\mathbf{5 0}$

\begin{tabular}{|l|c|c|c|c|c|}
\hline Test & Max. & \multicolumn{3}{|c|}{ Scores } & Paired \\
\hline & Score & Mean & SD & $\begin{array}{c}\text { Mean } \\
\text { difference }\end{array}$ & 't' Test \\
\hline Pre test & 20 & 7.04 & 1.4 & 4.02 & $20.30^{*}$ \\
\hline Post test & 20 & 3.00 & 2.5 & & $\mathrm{P}(<.05)$ \\
\hline
\end{tabular}

* Significant at $5 \%$ level,

Table -2 reveals, The mean PCCL after dietary intervention was 3.0 $(\mathrm{SD}=2.5)$ significantly less than the pre test $7.04(\mathrm{SD}=1.4), \mathrm{t}=$ $20.3(p<0.05)$. Therefore the null hypothesis was rejected and the dietary intervention was significantly effective in reducing PCCL among women.

Table : 3 Effectiveness of Dietary intervention on PCCL among Experimental and control group

$\mathbf{N}=\mathbf{1 0 0}$

\begin{tabular}{|l|c|c|c|c|}
\hline \multirow{2}{*}{ Group } & \multicolumn{3}{|c|}{ Post test - Pre test PCCL } & \multirow{2}{*}{$\mathrm{t}$} \\
\cline { 2 - 3 } & $\begin{array}{c}\text { Mean } \\
\text { difference }\end{array}$ & SD & $\begin{array}{c}\text { Difference in } \\
\text { mean difference }\end{array}$ & \\
\hline Experimental & 4.04 & 1.37 & 3.44 & 12.488 \\
\hline Control & 0.60 & 1.38 & & $\mathrm{P}<0.001$ \\
\hline
\end{tabular}

Table - 3 reveals, the obtained mean difference in PCCL among the experimental group 4.04 (SD =1.37) was significantly higher than the control group $0.60(\mathrm{SD}=1.38), \mathrm{t}=12.488(\mathrm{P}<.001)$. Therefore the null hypothesis was rejected and the dietary intervention was highly significant in reducing the PCCL among women.

Whereas in control group majority of women $26(52 \%)$ were in the age group of $20-30 y r s, 21(42 \%)$ had higher secondary education, 25(50\%) were private employees, $50(100 \%)$ were Hindus, 33(66\%) were in the income range of Rs1001-2000, 27(54\%) were belonging to Joint family, $48(96 \%)$ were non vegetarians, $21(42 \%)$ had habit of tobacco chewing, 38(76\%) were married at the age of 14 16yrs, $49(98 \%)$ had no family history of genital malignancies, 50(100\%) did not have post coital bleeding and $42(84 \%)$ did not have history of white discharge. In menstrual variables 44(88\%) had regular menstrual cycle, $29(58 \%)$ had attained menarche at the age of 13yrs, $41(82 \%)$ had normal menstrual flow, 34(68\%) were using cotton cloths during menstruation, 34(68\%) were reusing cloths used during periods, 34(68\%) were washing cloth with cold water and drying in sunlight, 24(48\%) were changing cloths after fully soaked and $50(100 \%)$ were taking bath daily once. In sexual practice variables majority $38(76 \%)$ were exposed to sex at the age of $15-16 y$ rs, $26(52 \%)$ were having sex once in 15 days, 26(52\%) were not washing perineal area after the sex, nobody had history of multiple sexual partner, nobody used condom during sex and nobody practiced sex during menstrual periods.

\section{Discussion}

In the present study it was observed that out of 50 women, in experimental group in the post test, 20(40\%) were in negative score, $30(60 \%)$ were in grade I PCCL or CIN-I. In control group out of 50 women in the post test it was observed that $15(30 \%)$ were in grade I PCCL or CIN-I and $35(70 \%)$ were in grade II PCCLor CIN-II.

Regarding PCCL status among rural women, the obtained mean difference in PCCL among the experimental group $4.04(\mathrm{SD}=1.37$ ) was significantly higher than the control group $0.60(S D=1.38) . t=12.488(P<.001)$. Therefore the null hypothesis was rejected and the dietary intervention was highly significant in reducing the PCCLamong women.

The obtained mean value in Post test PCCL among experimental group $3.0(S D=2.47$ ) was significantly higher than the control group 6.44 (SD = 2.11), $t=7.479$ ( $p<$ $0.001)$. Therefore the null hypothesis was rejected and the dietary intervention was highly significant in reducing Post test PCCL among women.

The finding of the study is supported by a study conducted in Brazil on Diet and serum micronutrients in relation to cervical neoplasia and cancer among low income women. Study reveals that Serum carotenoids and tocopherols are associated with risk for cervical neoplasia. Researcher evaluated the association of serum total carotene and tocopherols, and dietary intakes with the risk of newly diagnosed, histologically confirmed cervical intraepithelial neoplasia (CIN) grades 1, 2, 3 and invasive cancer in a hospital-based case-control study in São Paulo, Brazil. Sample size included 453 controls and 4 groups of cases (CIN1, n=140; CIN2, n=126; CIN3, n =231; invasive cancer, $n=108)$. Increasing concentrations of serum lycopene were negatively associated with CIN1, CIN3 and cancer, with odds ratios (OR) $(95 \% \mathrm{Cl})$ for the highest compared to the lowest tertile of $0.53(0.27-1.00, p$ for trend $=0.05), 0.48$ (0.22-1.04, $p$ for trend $=0.05)$ and $0.18(0.06-0.52, p$ for 
trend $=0.002$ ), respectively, after adjusting for confounding variables and HPV status. Increasing concentrations of serum alpha- and gamma-tocopherols, and higher dietary intakes of dark green and deep yellow vegetables/fruit were associated with nearly $50 \%$ decreased risk of CIN3. These results support the evidence that a healthy and balanced diet leading to provide high serum levels of antioxidants may reduce cervical neoplasia riskin low-income women ${ }^{14}$.

\section{References}

1. Dr. Basavanthappa B.T. Text book of Community Health Nursing. $1^{\text {st }}$ ed. New Delhi; Jaypee publications: 2001 pg. 205.

2. Cancer registry [online]. Available from: URL: http://www.cancer.gov 2010

3. David. Cervical cancer: [online]. Available from: URL:http:// thenationonlineng.net / web/3/author/david/WALE ADEPOJU 22/02/2011

4. Savitha Sharma. Vaccines against human papilloma virus and cervical cancer. Indian J com med [serial online] 2008 July [cited on 2008 sep19]; vol: 33.

5. Christine M iaskowski, Patricia buchsel, Oncology Nursing Assessment \& Clinical care, M osby, Philadelphia, first edition, copyright, 1999, St.Louis, M usouri, Chapter-29, Pagno 657-686.

6. Cervicalcancer-incidence. Availablefrom URL: http:// www.medindia.net/patients/patientinfo/cervicalcancerincidence.htm.

7. Kumaravalsomasundaram. HPV vaccine-end to women's major health problem. Indian J Med res 127, 2008 June; p.511.

8. Ferlay J, Bray.F, Pisani P, Parkin D M. GLOBOCAN 2000 : Cancer incidence, mortality and prevalence world wide. IARC press, 2001; version 1.0. IARC cancer Bare NO. 5.

9. Ministry of Health and Family welfare. National cancer control programme of India. New Delhi: Government of India, 1982.

10. National Cancer Registry Programme. Indian council for Medical Research 2001.

11. BMC Medical Research Methodology 2007, http:// www.biomedcentral.com/1471- 2288/7/36.

12. BBC News/ Health/Vinegar test for cervical cancer, mhtml:file:// H:/ vinegar.mht, pg 1-3.

13. www.ceu.ox.ac.uk/publications/41, 6/4/2010.

14. Tomita LY, Longatto Filo A, Costa M C, Andreoli M A, Villa LL, Franco EL, CardosoMA, BRINCA, Int JC Cancer. 2010 Feb1; 126(3): 703-14. Doi.10. 1002/ijc.24793, PM ID:19642096

\section{Conclusion}

Cervical cancer is one of the leading cancers among women, which affects approximately 4,90,000 women each year, resulting in approximately 2,70,000 deaths worldwide. VIA has proved to be useful as a cheap and effective screening test for cervical cancer. The overall findings of the study clearly showed that there was a significant reduction in PCCL scores after the administration of antioxidants. Thus the antioxidants is effective in reducing the PCCL among women. 